\title{
DETERMINAÇÃO DA ATIVIDADE ANTIMICROBIANA "IN VITRO" DE QUATRO ÓLEOS ESSENCIAIS DE CONDIMENTOS E ESPECIARIAS
}

\author{
FERNANDO LEITE HOFFMANN * \\ SÍLVIO JOSÉ FERREIRA DE SOUZA * \\ CRISPIN HUMBERTO GARCIA-CRUZ * \\ TÂNIA MARIA VINTURIM * \\ ALFENO LIMA DUTRA *
}

\begin{abstract}
Determinou-se a atividade antimicrobiana "in vitro" de quatro óleos essenciais de condimentos e especiarias (canela, cravo, gengibre e menta), em três diferentes concentrações $(10,0 ; 1,0$ e $0,1 \%)$ sobre vinte e um microrganismos (sete leveduras e quatorze bactérias). Para tanto, foram utilizados inóculos padronizados destas leveduras e bactérias, previamente crescidos em caldo nutriente e semeados pela técnica de plaqueamento em réplica, em placas de Petri contendo ágar nutriente + tween 20, sem tratamento (controle) e com as diferentes concentrações dos óleos essenciais estudados. Os resultados, obtidos após incubação a $30{ }^{\circ} \mathrm{C}$ por 30 dias, demonstraram que, dentro dos parâmetros utilizados no experimento, os óleos essenciais com maior atividade antimicrobiana foram os de canela e menta, nas concentrações de 10,0 e 1,0\%. O óleo de cravo também inibiu completamente o crescimento de todos os microrganismos testados na concentração de $10,0 \%$.
\end{abstract}

\section{INTRODUÇÃO}

Os temperos ou condimentos, utilizados como ingredientes na preparação de alimentos, desempenham importante papel em decorrência do aumento no consumo de produtos industrializados. Os temperos ou condimentos, assim como as especiarias, são substâncias de origem vegetal, geralmente

* Professores, Departamento de Engenharia e Tecnologia de Alimentos, Universidade Estadual Paulista (UNESP), São José do Rio Preto (SP). 
usadas para conferir sabor agradável aos alimentos. A indústria alimentícia utiliza normalmente condimentos preparados, prontos para uso, que podem ser obtidos pela simples mistura de substâncias naturais ou elaborados com a adição ou não de substâncias alimentícias. Estes condimentos apresentam-se sob a forma de pó, pasta ou molho, em emulsão ou suspensão (SÃO PAULO, 1978).

Os condimentos assim como as especiarias, sob o ponto de vista microbiológico, em contato com umidade e temperatura adequadas podem sofrer ataque de bolores ou microrganismos que propiciam a deterioração do alimento, acarretando moléstias ao consumidor. No entanto, alguns apresentam atividade antimicrobiana, que pode ajudar na conservação de alimentos, e outros ainda estimulam o metabolismo microbiano, tornando mais rápida a alteração e/ou formação de toxinas (ICMSF, 1980).

Diversos autores têm estudado a atividade antimicrobiana dos condimentos e/ou especiarias, assim como de seus óleos essenciais, que progressivamente têm sido adicionados aos alimentos como aromatizantes.

GALLI et al. (1985) testaram óleos e extratos (obtidos pela destilação e concentração à vácuo de infusões alcoólicas e aquosas, respectivamente) dos condimentos (80/20\% solução aquosa destilada) contra treze microrganismos Gram-negativos e Gram-positivos e treze leveduras e bolores em meio sólido. Com as bactérias Gram-negativas e Grampositivas houve efeito geralmente pequeno, sendo os bacilos e os clostrídios as linhagens mais sensíveis. Os bolores foram mais sensíveis ao efeito inibitório do que as leveduras (embora tenha gerado ampla divergência). Os óleos essenciais de mostarda e canela e extratos de zimbro apresentaram o efeito mais marcante. Quando a dose inibitória mínima foi determinada em extratos de louro e noz-moscada e óleos de canela, louro e tomilho, os valores foram geralmente $\geq 2000$ ppm.

Segundo BRIOZZO et al. (1989) o óleo essencial de cravo disperso em solução concentrada de açúcar $(0,4 \% \mathrm{v} / \mathrm{v})$ revelou efeito germicida marcante contra diversos organismos. Foram testados Candida albicans, Staphylococcus aureus (cinco linhagens), Klebsiella pneumoniae, Pseudomonas aeruginosa, Clostridium perfringens e Escherichia coli inoculadas a $10^{7} \mathrm{UFC} / \mathrm{mL}$ e Candida albicans (inóculo de 4,0 × $10^{5}$ UFC/mL), sendo quase todos mortos (>99,99\%) após 2-7 minutos, no laboratório em caldo suplementado com $63 \%$ de açúcar (v/p), contendo $0,4 \%$ de óleo essencial de cravo (v/p). A adição de matéria orgânica (por exemplo, soro humano ou bovino) não prejudicou a atividade antimicrobiana. O açúcar não foi necessário para a atividade antimicrobiana do óleo de cravo, mas a solução concentrada de açúcar produziu bom veículo para se obter dispersão de óleo, relativamente estável para certas aplicações práticas. 
Seis óleos essenciais de condimentos (sálvia, alecrim, alcaravia, cominho, cravo e tomilho) e seus ingredientes básicos foram testados quanto ao seu efeito inibidor contra três linhagens de bactérias Gram negativas, quatro linhagens de bactérias Gram positivas, uma bactéria produtora de ácido e uma cepa de levedura. Realizou-se a separação preliminar da atividade antimicrobiana dos óleos essenciais com disco de papel de filtro e o método de difusão em ágar. Mediu-se também a concentração mínima inibidora para cada óleo essencial contra vários microrganismos. As mais baixas concentrações $(0,25-12 \mathrm{mg} / \mathrm{mL})$ de vários óleos essenciais foram suficientes para prevenir o crescimento microbiano. Os dados mostraram que as bactérias Gram-positivas são mais sensíveis aos componentes antimicrobianos dos condimentos do que as Gram-negativas. As zonas de inibição de diferentes crescimentos microbianos produzidas por vários óleos essenciais foram similares àquelas produzidas por seus componentes básicos. Os óleos de tomilho e cominho apresentaram atividade antimicrobiana mais forte, quando comparados aos outros óleos essenciais. Houve afinidade entre as estruturas químicas dos componentes mais abundantes dos óleos essenciais investigados e a atividade antimicrobiana (FARAG et al., 1989).

MEENA e VIJAY (1994) estudaram a atividade antimicrobiana de óleos essenciais de condimentos sobre uma série de microrganismos, utilizando o método de difusão em disco de papel. Os óleos essenciais de condimentos como cominho, gengibre, coentro, manjericão e cravo, e também eugenol e alil-iso-tiocianato (óleo volátil de mostarda) foram pesquisados. Lactobacillus acidophilus, Bacillus cereus, Saccharomyces cerevisiae, Mycoderma sp e Aspergillus niger foram usados como organismos teste. Os óleos essenciais mostraram vários graus de inibição sobre os organismos teste. Mycoderma sp foi o mais susceptível e Bacillus cereus o mais resistente a todos os óleos essenciais de condimentos. A susceptibilidade seguiu a ordem Bacillus cereus, Lactobacillus acidophilus, Saccharomyces cerevisiae, Aspergillus niger e Mycoderma sp. Maior atividade antimicrobiana foi observada com o alil-iso-tiocianato, seguido do eugenol, ambos a temperatura ambiente e a $37^{\circ} \mathrm{C}$. Os óleos dos outros condimentos foram menos efetivos.

ISMAIEL (1988) testou os efeitos dos óleos essenciais de cravo, tomilho, pimenta preta, pimenta, orégano, alho, cebola e canela na germinação, crescimento pós-germinativo, crescimento e produção de toxina de Clostridium botulinum (seis linhagens dos tipos A, B e E) em meio microbiológico. O óleo de alho foi o mais potente inibidor da germinação. Aparentemente os óleos não apresentaram efeito significativo no crescimento pós-germinativo de esporos germinados, nem na produção de toxina. Os óleos de pimenta preta, cravo, canela e orégano foram os mais fortes inibidores do crescimento vegetativo. $O$ estudo revelou também o efeito da combinação do óleo de orégano e $\mathrm{NaNO}_{2}$ no crescimento e produção de toxina pelo Clostridium botulinum em sistemas modelo de 
carne. Em carne de porco empacotada à vácuo, 400 ppm de óleo de orégano combinado com 50-100 ppm de $\mathrm{NaNO}_{2}$ inibiram significativamente o crescimento e a produção de toxina.

ISMAIEL e PIERSON (1990) avaliaram os efeitos dos óleos de cravo, tomilho, pimenta preta, pimenta, orégano, alho, cebola e canela no crescimento e germinação de Clostridium botulinum, tipos 33A, 40B e 1623E. Em 200 ppm todos os óleos apresentaram alta inibição do crescimento de Clostridium botulinum (33A, 40B e 1623E). Em 10 ppm a atividade inibitória de muitos óleos diminuiu. Com relação a atividade de crescimento de Clostridium botulinum os óleos de canela, orégano e cravo mostraram-se muito ativos, os de pimenta e tomilho ativos, e os de alho, cebola e pimenta preta pouco ativos. A efetividade na germinação foi totalmente diferente. A 150 e 200 ppm todos os óleos preveniram completamente a germinação. Em 10 ppm, alho e cebola mostraram maior atividade que os outros óleos. Os esporos de 33A foram mais sensíveis que os de $40 \mathrm{~B}$ e $1623 \mathrm{E}$.

Os efeitos inibitórios de óleos essenciais de coentro, cravo, noz-moscada e pimenta sobre Aeromonas hydrophila, linhagens ISM 84331 (isolada clinicamente) e DIP 28 (isolada de peixe fresco) foram estudados em ágar triptic soja. Os óleos essenciais de cravo, coentro e noz-moscada, em concentrações respectivamente de 500; 1250 e $10000 \mu \mathrm{L} / \mathrm{mL}$ mostraramse efetivos para inibir o crescimento de Aeromonas hydrophila. Em pimenta, contendo o mínimo de óleo ativo, $15000 \mu \mathrm{g} / \mathrm{mL}$ foram necessárias para inibir a cultura diluída de Aeromonas hydrophila. O comportamento da Aeromonas hydrophila também foi avaliado em amostras de lombo de porco não curado e cozido, obtidas de uma planta local, cortadas em pedaços de $11 \times 6 \times 1 \mathrm{~cm}$, cozidas em banho de água a $75{ }^{\circ} \mathrm{C}$, por 30 minutos e tratadas com óleo de coentro ou de cravo. As amostras empacotadas à vácuo ou a ar foram armazenadas a 2 e $10{ }^{\circ} \mathrm{C}$. Os óleos essenciais de coentro e de cravo causaram redução no crescimento de Aeromonas hydrophila. Em amostras de carne tratadas com óleo de cravo e armazenadas a $10{ }^{\circ} \mathrm{C}$, o efeito letal foi significativamente aumentado pela embalagem à vácuo. Os dados evidenciaram que os óleos essenciais de coentro e de cravo poderiam ser usados para o controle de Aeromonas hydrophila em carne não curada cozida, em temperatura definida, especialmente se usados em combinação com embalagem à vácuo (STECCHINI et al., 1993).

Numa tentativa para identificar substâncias anticariogênicas, YOU et al., (1993) investigaram as atividades de algumas ervas medicinais e condimentos contra Streptococcus mutans. Os óleos essenciais de orégano, tomilho, sálvia, funcho, noz moscada, alecrim, cálamo e córtex de cássia mostraram atividade antibacteriana contra Streptococcus mutans. $\mathrm{O}$ óleo essencial de orégano foi o mais ativo. A concentração mínima inibitória do óleo essencial de orégano foi de $0,05 \mu \mathrm{L} / \mathrm{mL}$. 
DEANS e RITCHIE (1987) examinaram as propriedades antibacterianas de cinquenta óleos essenciais sobre vinte e cinco gêneros de bactérias. Para tanto, testaram quatro concentrações de cada óleo (não diluída e diluída a $1: 2$, 1:5 e 1:10 em etanol absoluto), utilizando técnica de difusão em ágar. Os dez óleos mais inibitórios foram os de tomilho, canela, louro, cravo, amêndoa (amarga), ligústica, pimentão, manjerona, angélica e nozmoscada. Os extratos mais abrangentemente inibitórios foram os de angélica (sobre vinte e cinco gêneros), louro (vinte e quatro), canela (vinte e três), cravo (vinte e três), tomilho (vinte e três), amêndoa amarga (vinte e dois), manjerona (vinte e dois), pimentão (vinte e dois), gerânio (vinte e um) e ligústica (vinte).

A atividade antimicrobiana de trinta e dois óleos essenciais de plantas, comumente usadas nas indústrias de alimentos, foi examinada em quatro linhagens de Listeria monocytogenes e uma linhagem de Listeria innocua, mediante dois procedimentos (método de difusão em disco de papel e a curva de inibição). No primeiro procedimento foi testada uma solução etanólica absoluta $(1: 5 \mathrm{v} / \mathrm{v})$ de cada óleo em placas inoculadas com bactérias na concentração de $10^{6} \mathrm{UFC} / \mathrm{mL}$. Cinco dos trinta e dois óleos essenciais (canela, cravo, orégano, pimentão e tomilho) mostraram atividade antibacteriana. O estudo da curva de inibição, em sistema de solução salina, evidenciou atividade marcada e rápida (geralmente com uma hora de exposição) para óleo de pimentão e atividade lenta para os óleos de cravo, orégano e tomilho. A atividade antilistérica dos óleos testados com a linhagem dependente obedeceu o mesmo comportamento. A linhagem de Listeria monocytogenes, testada em alimento matriz (carne de porco picada) e óleo essencial de tomilho, reduziu esta população em aproximadamente cem vezes na primeira semana de estocagem (AURELI et al., 1992).

MOLEYAR e NARASIMHAM (1992) pesquisaram a atividade antibacteriana de quinze óleos essenciais sobre Staphylococcus $s p$, Micrococcus sp, Bacillus sp e Enterobacter sp, pela técnica de plaqueamento em ágar. O aldeído cinâmico foi o componente mais ativo seguido por citral, geraniol, eugenol e mentol. Em $500 \mu \mathrm{g} / \mathrm{mL}$ o aldeído cinâmico inibiu completamente o crescimento bacteriano por mais de 30 dias a $30{ }^{\circ} \mathrm{C}$, comparado com $200 \mu \mathrm{g} / \mathrm{mL}$ de butil hidroxi anisol (BHA). A 25 e $20{ }^{\circ} \mathrm{C}$ a atividade antibacteriana de cinco óleos essenciais aumentou. $A$ adição de cloreto de sódio a $4 \%$ no meio $(\mathrm{p} / \mathrm{v})$ não teve efeito na atividade inibitória do aldeído cinâmico. Em misturas de aldeído cinâmico e eugenol ou BHA foi observado efeito aditivo.

BAYOUMI (1992) estudou os efeitos de quatro óleos essenciais (cravo, canela, cardamomo e hortelã-pimenta) no crescimento de culturas produtoras de ácido láctico (Streptococcus thermophilus e Lactobacillus bulgaricus), juntamente com a utilização destes óleos essenciais na fabricação de iogurte flavorizado. O óleo de canela foi o mais efetivo 
agente antibacteriano contra Streptococcus thermophilus e Lactobacillus bulgaricus, com completa inibição do crescimento bacteriano em leite na concentração de $0,5-10 \%$, seguido pelos óleos de cardamomo, de cravo e de hortelã. A atividade antibacteriana foi influenciada pela espécie bacteriana e pela concentração de óleos essenciais. Amostras de iogurte com boa consistência, aparência e sabor foram obtidas pela adição de preparações de flavorizantes hidrossolúveis de cravo, hortelã-pimenta e canela a respectivamente 0,$5 ; 0,4$ e $1,0 \mathrm{~g} / \mathrm{Kg}$ de leite. Para cardamomo, a melhor concentração foi de $0,5-0,7 \mathrm{~g} / \mathrm{Kg}$ de leite. A vida de prateleira dos iogurtes flavorizados foi de quinze dias a $10{ }^{\circ} \mathrm{C}$ ou vinte e seis dias a $6{ }^{\circ} \mathrm{C}$.

O presente trabalho teve como objetivo determinar a atividade antimicrobiana "in vitro" de quatro óleos essenciais de condimentos e especiarias (canela, cravo, gengibre e menta) da mesma marca comercial, em três diferentes concentrações $(10,0 ; 1,0$ e $0,1 \%)$, sobre vinte e um microrganismos (sete leveduras e quatorze bactérias).

\section{MATERIAL E MÉTODOS}

\subsection{OBTENÇÃO DOS MICRORGANISMOS}

As leveduras utilizadas foram cedidas pelo Prof. Dr. Allen Norton Hagler, do Instituto de Microbiologia da Universidade Federal do Rio de Janeiro, ao passo que as bactérias pertenciam à coleção de culturas do Laboratório de Microbiologia de Alimentos - DETA/UNESP, São José do Rio Preto (SP), Brasil.

\subsection{ENSAIO DE RESISTÊNCIA AOS ÓLEOS ESSENCIAIS DE CONDIMENTOS E ESPECIARIAS}

Para esta prova foram utilizados inóculos padronizados de vinte e um microrganismos (sendo sete leveduras e quatorze bactérias), previamente crescidos a $30{ }^{\circ} \mathrm{C}$, por 24 horas, em caldo nutriente. Os mesmos foram inoculados pela técnica de plaqueamento em réplica, em placas de Petri contendo ágar nutriente + tween 20 , sem tratamento (controle) e com três diferentes concentrações $(10,0 ; 1,0$ e $0,1 \%)$ dos quatro óleos essenciais de condimentos e especiarias (canela, cravo, gengibre e menta). Todas as placas semeadas, posteriormente foram incubadas a $30^{\circ} \mathrm{C}$, por 30 dias, com a finalidade de se verificar a resistência ou não dos microrganismos frente aos produtos testados. 
O comportamento dos microrganismos frente aos diferentes produtos e/ou concentrações testadas encontram-se na Tabela 1.

Verificou-se crescimento de todos os vinte e um microrganismos (100\%) nas placas de Petri contendo somente o meio de cultura (controle). Todos os microrganismos testados mostraram-se sensíveis aos óleos essenciais de canela e menta, nas concentrações de 10,0 e 1,0\%, assim como ao óleo essencial de cravo, na concentração de 10,0\%. Tais resultados são semelhantes aos encontrados por BAYOUMI (1992), confirmando a eficácia dos óleos de canela e cravo como agentes antimicrobianos.

Todos os microrganismos estudados apresentaram resistência ao óleo essencial de gengibre, nas três concentrações testadas.

\title{
4 CONCLUSÃO
}

De acordo com os resultados obtidos, após incubação a $30{ }^{\circ} \mathrm{C}$ por 30 dias, verificou-se que os óleos essenciais com maior atividade antimicrobiana foram os de canela e menta, nas concentrações de 10,0 e 1,0\%. O óleo essencial de cravo, na concentração de 10,0\% também inibiu completamente o crescimento de todos os microrganismos testados.

O óleo essencial de gengibre, nas concentrações empregadas, não se mostrou eficiente como agente antimicrobiano.

\begin{abstract}
The in vitro antimicrobial activity was determined for essential oils of cinnamon, clove, ginger, and mint using three different concentrations (10.0, 1.0 and $0.1 \%)$ on twenty-one microorganisms (seven species of yeasts, and 14 species of bacteria). The study involved standardized inoculum of microorganisms - previously grown in nutrient broth and sown through the "in replica plating technique" in Petri dishes containing nutrient agar plus tween 20 - with no treatment (control) and with addition of the different concentrations of essential oils. The results obtained after incubation at $30^{\circ} \mathrm{C}$ for thirty days showed that, within the parameters used in the experiment, the essential oils of cinnamon and mint presented the highest antimicrobial activity in the concentrations of 10.0 and $1.0 \%$, followed by that from clove in the concentration of $10.0 \%$, which also completely inhibited the growth of all the tested microorganisms.
\end{abstract}




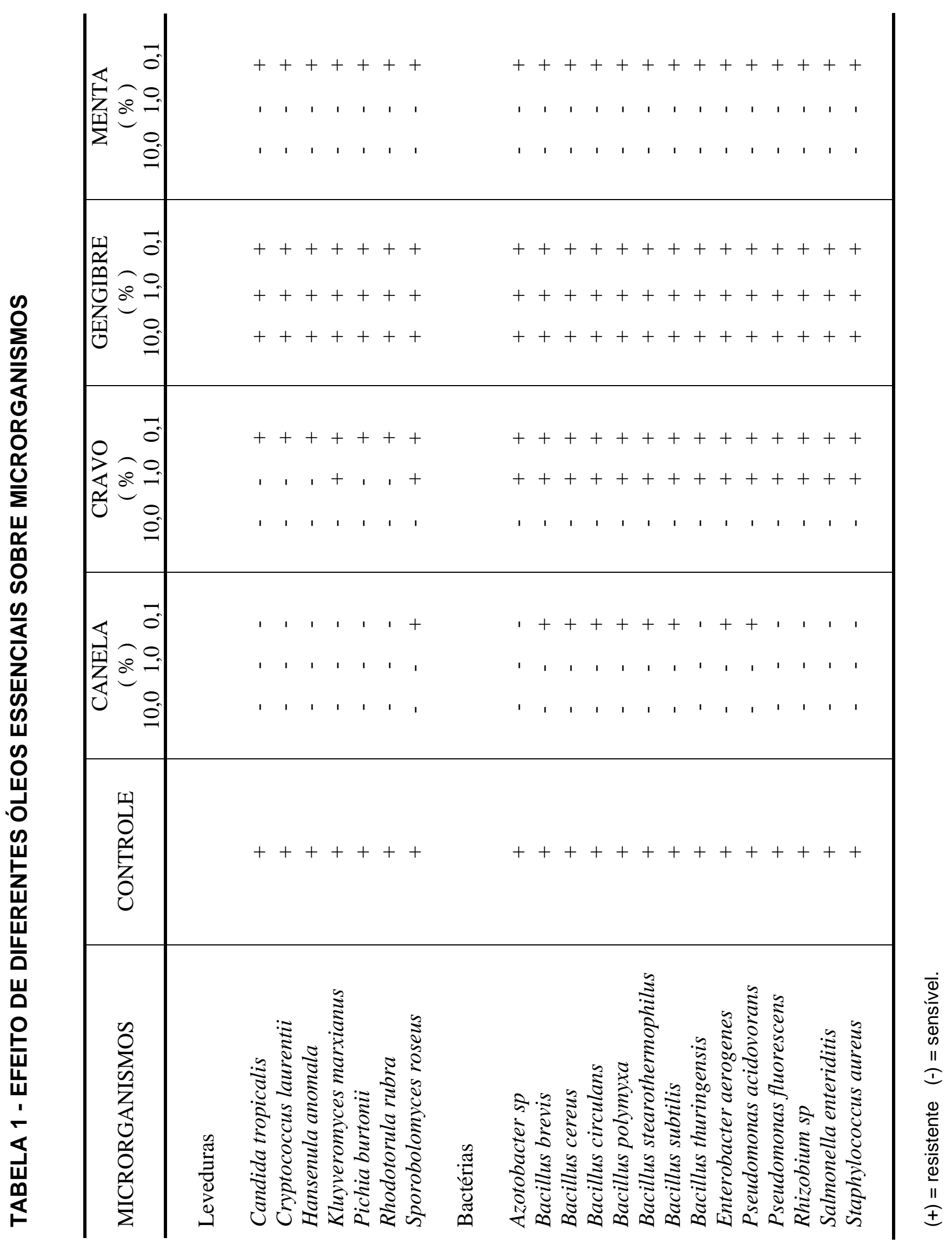




\section{REFERÊNCIAS BIBLIOGRÁFICAS}

1 AURELI, P., COSTANTINI, A., ZOLEA, S. Antimicrobial activity of some plant essential oils against Listeria monocytogenes. Journal of Food Protection, v. 55, n. 5, p. 344-348, 1992.

2 BAYOMI, S. Bacteriostatic effect of some spices and their utilization in the manufacture of yoghurt. Chemie Mikrobiologie Technologie der Lebensmittel, v. 14, n. 1/2, p. 21-26, 1992.

3 BRIOZZO, J., NUNEZ, L., CHIRIFE, J., HERSZAGE, L., D'AQUINO, M. Antimicrobial activity of clove oil dispersed in a concentrated sugar solution. Journal of Applied Bacteriology, v. 66, n. 1, p. 69-75, 1989.

4 DEANS, S.G., RITCHIE, G. Antibacterial properties of plant essential oils. International Journal of Food Microbiology, v. 5, n. 2, p. 165-180, 1987.

5 FARAG, R.S., DAW, Z.Y., HEWEDI, F.M., EL-BAROTY, G.S.A. Antimicrobial activity of some egyptian spice essential oils. Journal of Food Protection, v. 52, n. 9, p. 665-667, 1989.

6 GALLI, A., FRANZETTI, L., BRIGUGLIO, D. In vitro antimicrobial activity of essential oil and extracts of spices used in foods. Industrie Alimentari, v. 24, n. 277, p. 463-466, 1985.

7 INTERNATIONAL COMMISSION ON MICROBIOLOGICAL SPECIFICATIONS FOR FOODS (ICMSF). Microbial ecology of foods. New York: Academic Press, 1980. v. 2.

8 ISMAIEL, A., PIERSON, M.D. Inhibition of growth and germination of C. botulinum 33A, 40B, and 1623E by essential oil of spices. Journal of Food Science, v. 55, n. 6, p. 1676-1678, 1990.

9 ISMAIEL, A.A. The inhibition of Clostridium botulinum growth and toxin production by essencial oil of spice. Dissertation Abstracts International, B 48, v. 10, p. 2834, 1988.

10 ISMAIEL, A.A., PIERSON, M.D. Inhibition of germination outgrowth, and vegetative growth of Clostridium botulinum 67B by spice oils. Journal of Food Protection, v. 53, n. 9, p. 755-758, 1990.

11 MEENA, M.R., VIJAY SETHI. Antimicrobial activity of essential oils from spices. Journal of Food Science and Technology, India, v. 31, n. 1, p. 68-70, 1994. 
12 MOLEYAR, V., NARASIMHAM, P. Antibacterial activity of essential oil components. International Journal of Food Microbiology, v. 16, n. 4, p. 337-342, 1992.

13 SÃO PAULO (Estado). Decreto n. 12486, de 20 de outubro de 1978. Aprova normas técnicas especiais relativas a alimentos e bebidas. Diário Oficial, São Paulo, p. 1-42, 21 out. 1978.

14 STECCHINI, M.L., SARAIS, I., GIAVEDONI, P. Effect of essential oil on Aeromonas hydrophila in a culture medium and in cooked pork. Journal of Food Protection, v. 35, n. 5, p. 406-409, 1993.

15 YOU, Y.S., PARK, K.M., KIM, Y.B. Antimicrobial activity of some medical herbs and spices against Streptococcus mutans. Korean Journal of Applied Microbiology and Bioengineering, v. 21, n. 2, p. 187-191, 1993. 